\title{
Associations between three specific a-cellular measures of the oxidative potential of particulate matter and markers of acute airway and nasal inflammation in healthy volunteers
}

\author{
Nicole A H Janssen, ${ }^{1}$ Maciej Strak, ${ }^{1,2,3}$ Aileen Yang, ${ }^{1,2}$ Bryan Hellack, ${ }^{4,5}$ \\ Frank J Kelly, ${ }^{6}$ Thomas A J Kuhlbusch, ${ }^{4,5}$ Roy M Harrison, 7,8 Bert Brunekreef, ${ }^{2,9}$ \\ Flemming R Cassee, ${ }^{1,2}$ Maaike Steenhof, ${ }^{2}$ Gerard Hoek $^{2}$
}

- Additional material is published online only. To view please visit the journal online (http://dx.doi.org/10.1136/ oemed-2014-102303).

For numbered affiliations see end of article.

\section{Correspondence to}

Dr Nicole AH Janssen, National Institute for Public Health and the Environment (RIVM), PO Box 1, Bilthoven 3720 BA, The Netherlands; Nicole.Janssen@ rivm.nl

Received 1 May 2014 Revised 8 July 2014 Accepted 23 July 2014 Published Online First 7 August 2014

\section{ABSTRACT}

Introduction We evaluated associations between three a-cellular measures of the oxidative potential (OP) of particulate matter (PM) and acute health effects. Methods We exposed 31 volunteers for $5 \mathrm{~h}$ to ambient air pollution at five locations: an underground train station, two traffic sites, a farm and an urban background site. Each volunteer visited at least three sites. We conducted health measurements before exposure, $2 \mathrm{~h}$ after exposure and the next morning. We measured air pollution on site and characterised the $\mathrm{OP}$ of $\mathrm{PM}_{2.5}$ and $\mathrm{PM}_{10}$ using three a-cellular assays; dithiotreitol $\left(\mathrm{OP}^{\mathrm{DTT}}\right)$, electron spin resonance $\left(\mathrm{OP}^{\mathrm{ESR}}\right)$ and ascorbic acid depletion $\left(\mathrm{OP}^{\mathrm{AA}}\right)$.

Results In single-pollutant models, all measures of OP were significantly associated with increases in fractional exhaled nitric oxide and increases in interleukin- 6 in nasal lavage $2 \mathrm{~h}$ after exposure. These OP associations remained significant after adjustment for co-pollutants when only the four outdoor sites were included, but lost significance when measurements at the underground site were included. Other health end points including lung function and vascular inflammatory and coagulation parameters in blood were not consistently associated with OP.

Conclusions We found significant associations between three a-cellular measures of OP of PM and markers of airway and nasal inflammation. However, consistency of these effects in two-pollutant models depended on how measurements at the underground site were considered. Lung function and vascular inflammatory and coagulation parameters in blood were not consistently associated with OP. Our study, therefore, provides limited support for a role of $\mathrm{OP}$ in predicting acute health effects of PM in healthy young adults.

\section{INTRODUCTION}

Numerous studies have shown health effects related to exposure to ambient particulate matter (PM). ${ }^{12}$ However, it is not well known which PM characteristics are responsible for the observed effects, ${ }^{3-5}$ although various PM characteristics, such as particle number concentrations (PNC), transition metals, organic components and biological components have been proposed.

\section{What this paper adds}

- The oxidative potential (OP) of particulate matter (PM) has been proposed as a more health relevant metric than PM mass.

- However, there is still limited evidence in epidemiological studies that the OP of PM is more closely associated with health effects than PM mass or individual PM characteristics.

- We found significant associations between three a-cellular measures of OP of PM and markers of airway and nasal inflammation in healthy young adults.

- These OP associations remained significant after adjustment for co-pollutants when only the four outdoor sites were included, but lost significance when measurements at the underground site were included.

- Other health end points, including lung function and vascular inflammatory and coagulation parameters in blood were not consistently associated with OP.

Oxidative stress has been suggested as an important underlying mechanism by which exposure to PM may lead to adverse health effects. ${ }^{67}$ Oxidative stress results when the generation of reactive oxygen species (ROS), or free radicals, exceeds the available antioxidant defences. High levels of oxidative stress induce inflammatory responses via a cascade of events including activation of various transcription factors and stimulation of cytokine production. ${ }^{6}$ The oxidative potential (OP), defined as a measure of the capacity of PM to oxidise target molecules, has been proposed as a metric that is more closely related to biological responses to PM exposures and thus could be more informative than PM mass alone. ${ }^{8}$ Several methods for measuring OP have been developed, both a-cellular and cellular. No consensus has been reached yet as to which measures of OP are most appropriate to predict PM-related health effects. ${ }^{9}$ Also, issues such as high variability in time and space and high costs of the different assays currently hamper wide-scale use. ${ }^{10}$ 
Although OP is considered an attractive measure, there is still limited evidence from epidemiological studies that it predicts health effects better than PM mass or individual PM characteristics. Two panel studies in California, USA, found an association between measures of OP and biomarkers of airway or systemic inflammation. ${ }^{11}{ }^{12}$ In a series of papers investigating acute effects of being exposed for $5 \mathrm{~h}$ to air pollution at different locations on a range of respiratory, ${ }^{13}$ nasal pro-inflammatory ${ }^{14}$ and vascular inflammatory and coagulation parameters ${ }^{15}$ in healthy volunteers, no consistent associations with OP for any of the evaluated health end points were reported. In these studies, OP of $\mathrm{PM}_{10}$ was calculated as the sum of OP from $\mathrm{PM}_{0.18}, \mathrm{PM}_{0.18-2.5}$ and $\mathrm{PM}_{2.5-10}$ collected with a Micro-Orifice Impactor (MOI) and measured as the capacity of PM to deplete the antioxidants ascorbate and glutathione in a synthetic human respiratory tract lining fluid (RTLF). We recently conducted additional measurements of $\mathrm{OP}$ in that study, using both $\mathrm{PM}_{2.5}$ and $\mathrm{PM}_{10}$ filters from Harvard Impactors (HIs) and three measures of OP: consumption of dithiotreitol (DTT), formation of hydroxyl radicals by electron spin resonance (ESR) and depletion of ascorbic acid (AA). ${ }^{16}$ These methods will be referred to as $\mathrm{OP}^{\mathrm{DTT}}, \mathrm{OP}^{\mathrm{ESR}}$ and $\mathrm{OP}^{\mathrm{AA}}$, respectively. Contrasts in $\mathrm{OP}$ among sites, differences in size fractions and correlations with PM composition depended on the specific OP assay, suggesting that the different assays can provide different information regarding the oxidative properties of PM. ${ }^{16}$

Here, we investigated associations between OP of $\mathrm{PM}_{2.5}$ and $\mathrm{PM}_{10}$ and acute changes in respiratory, nasal pro-inflammatory, vascular inflammatory and coagulation parameters, using three different measurement methods for OP: OP ${ }^{\mathrm{DTT}}$, OP ${ }^{\mathrm{ESR}}$ and $\mathrm{OP}^{\mathrm{AA}}$. We studied these associations in healthy volunteers, exposed for $5 \mathrm{~h}$ to ambient air pollution at selected real-world locations with substantial differences in OP and other PM characteristics. $^{16} 17$ We hypothesised that these OP measures will have attributable value to predict PM-related health effects.

\section{METHODS}

\section{Study design}

The study was conducted within the framework of the 'Risk of Airborne Particles: a Toxicological-Epidemiological hybrid Study' (RAPTES). The RAPTES study design has been described previously. ${ }^{13-15}$ In brief, we exposed 31 healthy volunteers to ambient air pollution at five different sites in the Netherlands: an underground train station, an animal farm, a continuous traffic site, a stop and go traffic site and an urban background site. The rationale for selecting different sites was to create high contrast and low correlations among different air pollutants. ${ }^{17}$ Site visits were performed on 30 week days from March to November 2009. Each sampling day, we visited one site and each site was visited at least five times. Volunteers were healthy, non-smoking students living at the campus of Utrecht University. Participants participated in 3-7 visits scheduled at least 14 days apart for each individual. Exposure started around 09:00 and lasted for $5 \mathrm{~h}$. Participants performed moderate exercise (minute ventilation $20 \mathrm{~L} / \mathrm{min} / \mathrm{m}^{2}$ ) on a bicycle ergometer for $20 \mathrm{~min}$ every hour. We chose a $5 \mathrm{~h}$ exposure period with intermittent exercise in order to increase the contrast with exposure outside of the study. We conducted measurements of lung function and $\mathrm{FE}_{\mathrm{NO}}$, as well as collected blood and nasal lavage (NAL) samples before exposure, $2 \mathrm{~h}$ after exposure and the next morning.

During each $5 \mathrm{~h}$ exposure, we performed a detailed characterisation of air pollution on-site. In addition to the characterisation previously, ${ }^{13-15}$ we measured $\mathrm{OP}$ of $\mathrm{PM}_{2.5}$ and $\mathrm{PM}_{10}$ using three a-cellular assays; $\mathrm{OP}^{\mathrm{DTT}}, \mathrm{OP}^{\mathrm{ESR}}$ and $\mathrm{OP}^{\mathrm{AA}} \cdot{ }^{16}$

\section{Exposure assessment}

PM mass, PM composition and gaseous air pollution

Details about the air pollution measurements are described elsewhere. ${ }^{13}{ }^{16}$ In brief, we collected $\mathrm{PM}_{2.5}$ and $\mathrm{PM}_{10}$ samples using HIs and measured endotoxin content of the $\mathrm{PM}_{10}$ samples. We analysed $\mathrm{PM}_{2.5-10}$ and $\mathrm{PM}_{2.5}$ samples collected with a high volume sampler for EC, OC, metals (eg, Fe, Cu), PAHs, nitrate and sulfate. We measured PNC and gaseous pollutants $\left(\mathrm{O}_{3}, \mathrm{NO}_{2}\right)$ using real-time monitors (PNC: CPC model 3022A; $\mathrm{O}_{3}$ : UV Photometric $\mathrm{O}_{3}$ Analyzer model 49, Thermo Environmental Instruments; $\mathrm{NO}_{\mathrm{x}}$ : Chemiluminescence $\mathrm{NO} /$ $\mathrm{NO}_{2} / \mathrm{NO}_{\mathrm{x}}$ analyser model $200 \mathrm{E}$, Teledyne API).

\section{Oxidative potential}

Measurement methods for the characterisation of OP are described in detail elsewhere. ${ }^{16}{ }^{18}$ In brief, we extracted $\mathrm{PM}_{10}$ and $\mathrm{PM}_{2.5}$ Teflon filters with methanol and resuspended with traceselect ultrapure water to a fixed concentration of $500 \mu \mathrm{g} / \mathrm{mL}$.

For OP ${ }^{\mathrm{DTT}}$, PM suspensions are incubated with DTT and the reaction is stopped at designated time points $(0,10,20$ and $30 \mathrm{~min})$. The absorbance at $412 \mathrm{~nm}$ is recorded on a spectrophotometer and the rate of DTT consumption is calculated using linear regression of absorbance against time. For OP ${ }^{\mathrm{ESR}}$, PM suspensions are diluted to $125 \mu \mathrm{g} / \mathrm{mL}$ and mixed with $\mathrm{H}_{2} \mathrm{O}_{2}$ and 5,5-dimethylpyrroline- $\mathrm{N}$-oxide. After incubation, the suspension is vortexed and transferred into a $50 \mu \mathrm{L}$ glass capillary without any filtration. The DMPO-OH quartette signal is measured with a MiniScope MS-400 spectrometer. OP ${ }^{\mathrm{ESR}}$ is calculated as the average of the total amplitudes of the DMPO-OH quartette in arbitrary units per $\mu \mathrm{g}$ PM. For $\mathrm{OP}^{\mathrm{AA}}$, PM suspensions are diluted to $12.5 \mu \mathrm{g} / \mathrm{mL}$ and incubated in a spectrophotometer. After adding AA, the absorption at $265 \mathrm{~nm}$ is measured every $2 \mathrm{~min}$ for $2 \mathrm{~h}$. The maximum depletion rate of AA is determined by performing a linear regression of the linear section of absorbance against time.

For all assays, the results were initially expressed as $\mathrm{OP} / \mu \mathrm{g}$. Field blank corrected OP values in $\mathrm{OP} / \mu \mathrm{g}$ were multiplied with the PM mass concentration $\left(\mu \mathrm{g} / \mathrm{m}^{3}\right)$ to calculate $\mathrm{OP} / \mathrm{m}^{3} .88 \%$ $\left(\mathrm{OP}^{\mathrm{DTT}}\right)$ to $97 \%\left(\mathrm{OP}^{\mathrm{AA}}\right)$ of the samples were above the detection limit. Coefficients of variation of field duplicates ranged from $8 \%$ for $\mathrm{OP}^{\mathrm{AA}}$ to $18 \%$ for $\mathrm{OP}^{\mathrm{DTT}}{ }^{16}$ Extreme outlying $\mathrm{OP}^{\mathrm{PM} 10}$ values from one measurement day at the farm were excluded. $^{16}$

\section{Health assessment}

Details about the health measurements are given elsewhere. ${ }^{13-15}$ In brief, we measured $\mathrm{FE}_{\mathrm{NO}}$, lung function ${ }^{13}$; interleukin (IL)-6, total protein and lactoferrin in NAL ${ }^{14}$; IL- 6 and high-sensitivity $\mathrm{C}$ reactive protein (CRP) in serum ${ }^{14}{ }^{15}$; Fibrinogen, von Willebrand Factor (vWF) antigen and the complex between tissue plasminogen activator and plasminogen activator inhibitor-1 (tPA/PAI-1) in citrate plasma ${ }^{15}$ and platelets as part of complete blood cell counts. ${ }^{15}$ Health parameters were expected to increase in relation to air pollution, with the exception of lung function (expected decrease), although decreases in blood IL- 6 have also been reported. ${ }^{14}$

\section{Data analysis}

We analysed the associations between OP of PM during exposure and health end points following the same data analysis strategy as used in previous papers on respiratory and vascular 
health outcomes within the RAPTES project. ${ }^{13-15}$ In brief, the difference in health parameters between postexposure and preexposure was used as the dependent variable in mixed linear regression to account for the influence of repeated observations per subject (using compound symmetry of the residuals). The $5 \mathrm{~h}$ average concentrations of air pollutants measured on-site were used as independent variables.

First, we analysed all health parameters in single-pollutant models:

- Respiratory parameters: $\mathrm{FE}_{\mathrm{NO}}, \mathrm{FVC}$ and $\mathrm{FEV}_{1}{ }^{13}$;

- Markers in NAL: IL-6, protein and lactoferrin ${ }^{14}$;

- Blood markers: CRP, fibrinogen platelets, vWF, TPA/PAI1 complex, ${ }^{15}$ IL-6. ${ }^{14}$

For the respiratory and NAL markers, we analysed effects $2 \mathrm{~h}$ after exposure, whereas for the blood markers we analysed effects the next morning, as these time points showed the strongest associations in our previous analyses.

We made the following modifications and additions to the previously described analysis strategy:

1. Log-transformation of exposure variables. The distributions of the different measures of $\mathrm{OP}$ as well as several other PM characteristics (eg, $\mathrm{Fe}, \mathrm{Cu}$ ) were highly skewed. We evaluated whether log-transformation of exposure improved the fit of the models by comparing the Akaike information criterion (AIC) (see online supplementary table $\mathrm{S} 1$ for $\mathrm{FE}_{\mathrm{NO}}$ and table S2 for NAL IL-6). Log-transformation of exposure resulted in a lower AIC for all measures of OP and most other exposure variables in the all sites as well as in the outdoor only models.

2. Additional adjustment for endotoxin for NAL parameters and blood IL-6 (ie, the parameters previously reported by Steenhof et $\left.a l^{14}\right)$. Highly elevated levels of endotoxin were observed at the farm site, which were significantly positively associated with NAL IL-6 and significantly negatively associated with serum IL-6. Rather than excluding the observations from the farm, ${ }^{14}$ we adjusted for endotoxin in all models investigating the associations with NAL and serum IL-6. Results after excluding the farm were similar (see online supplementary table S3).

3. Additional adjustment for exposure at the underground. As the underground site, compared to each outdoor site, had substantially higher concentrations of nearly all exposure parameters, we analysed the data separately after excluding the underground location (outdoor data set), as was done in our previous papers. In the current paper we added a third model, where we included 'measurement at the underground' as a dummy variable in the model. Inclusion of this variable resulted in a lower AIC for all measures of OP and most other exposure variables (see online supplementary table S1 for $\mathrm{FE}_{\mathrm{NO}}$ and table S2 for NAL IL-6).

We included the same confounding factors as in our previous analyses of the respective health parameters (ie, temperature, relative humidity and season for all parameters; pollen and respiratory infections for $\mathrm{FE}_{\mathrm{NO}}$ and lung function; use of oral contraceptives for all blood parameters except IL- $6^{13-15}$ ), with the addition of endotoxin in the models for NAL and serum IL-6, as described above. Post- and pre-exposure values of NAL IL-6, lactoferrin and all blood parameters were log-transformed to reduce the effect of outliers. ${ }^{13-15}$ A comparison between the previously published results and results using the modified data analysis strategy for the previously reported OP concentrations (ie, OP ${ }^{\mathrm{RTLF}}$, measured on MOI filters) was made to assess potential differences.

\section{Two-pollutant models}

We further evaluated associations in two-pollutant models for those health parameters that were significantly associated with at least one of the measures of OP. We specified two-pollutant models for $\mathrm{PM}_{2.5}$ and $\mathrm{PM}_{10}$ separately, that is, we adjusted associations for OP of $\mathrm{PM}_{2.5}$ for $\mathrm{PM}_{2.5}$ mass and $\mathrm{PM}_{2.5}$ composition and associations for $\mathrm{OP}$ of $\mathrm{PM}_{10}$ for $\mathrm{PM}_{10}$ mass and $\mathrm{PM}_{10}$ composition. Adjustment for $\mathrm{PNC}, \mathrm{NO}_{2}$ and $\mathrm{O}_{3}$ was done for both OP of $\mathrm{PM}_{2.5}$ and $\mathrm{OP}$ of $\mathrm{PM}_{10}$. We considered an association consistent if the $\mathrm{p}$ value in the one-pollutant model was smaller than 0.1 and remained so after adjusting for all other co-pollutants in two-pollutant models. Models in which two pollutants had a Spearman's rank correlation coefficient $>0.7$ were not interpreted, because including highly correlated variables may result in unstable effect estimates (co-linearity).

We present effect estimates and their 95\% CI as percentage increases over our study population mean of the baseline $(t=0)$ values. We express these values as percentage increases per changes in IQRs in the log-transformed concentrations. We express results from all analyses using the IQRs of the outdoor data set to allow direct comparison of effect estimates between the outdoor data set and the data set including all sites. Statistical significance was defined as $\mathrm{p}<0.05$ and borderline significance as $\mathrm{p}<0.10$. We performed all analyses using SAS 9.3 (SAS Institute, Cary, North Carolina, USA).

\section{RESULTS}

We obtained 170 observations from 31 volunteers ( 21 female; 10 male). Each participant participated 3-7 times. Mean age was 22 (range 19-26) years. Baseline levels of the different health parameters are given in the online supplementary table S4.

Geometric means and ranges of air pollutants during the $5 \mathrm{~h}$ exposures are presented in table 1 for OP, PM mass, PNC, $\mathrm{NO}_{2}$ and $\mathrm{O}_{3}$, and in the online supplementary table S5 for PM composition. We found highly elevated $\mathrm{OP}$ at the underground site for all three $\mathrm{OP}$ measures. PNC and $\mathrm{NO}_{2}$ concentrations were not (substantially) elevated at the underground site compared with the outdoor sites, whereas $\mathrm{O}_{3}$ was lower at the underground. Correlations between air pollution concentrations are shown in online supplementary table $\mathrm{S} 6$ for $\mathrm{PM}_{2.5}$ and $\mathrm{S} 7$ for $\mathrm{PM}_{10}$. More details about correlations between the three OP measures and their correlation with PM composition are presented and discussed elsewhere. ${ }^{16}$ In brief, when data from all sites were considered, we observed high correlations among all OP measures (Spearman R 0.80-0.97), which were partly driven by the high $\mathrm{OP}$ values at the underground site. When only the outdoor sites were considered, $\mathrm{OP}^{\mathrm{DTT}}$ was moderately correlated with $\mathrm{OP}^{\mathrm{ESR}}$ and $\mathrm{OP}^{\mathrm{AA}}$ (Spearman $\mathrm{r}$ 0.52-0.70), whereas $\mathrm{OP}^{\mathrm{ESR}}$ and $\mathrm{OP}^{\mathrm{AA}}$ were highly correlated (Spearman $\mathrm{r}$ $0.88-0.94)$.

\section{SINGLE-POLLUTANT MODELS}

Measures of OP were significantly $(p<0.05)$ associated with increases in $\mathrm{FE}_{\mathrm{NO}}$ or NAL IL-6 $2 \mathrm{~h}$ after exposure, with for NAL IL-6 the exception of OP ${ }^{\mathrm{ESR}}$ of $\mathrm{PM}_{2.5}$ (p 0.06-0.21) and OPAA of $\mathrm{PM}_{2.5}$ in the outdoor only data set $(\mathrm{p}=0.097)$ (table 2$)$. Effect estimates increased considerably after excluding the observations from the underground. When associations in the all sites data set were additionally adjusted for measurement at the underground (yes/no), effect estimates were generally similar to effects observed in the outdoor data set.

Significant associations between OP and lung function parameters $\left(\mathrm{FVC}, \mathrm{FEV}_{1}\right.$ ) were observed in the outdoor data set and/ or underground adjusted models, whereas NAL-lactoferrin was significantly associated with OP in the all sites data set.

None of the blood markers showed significant associations with OP in the outdoor data set and/or underground adjusted 
Table 1 Geometric mean and range (minimum-maximum) of $5 \mathrm{~h}$ average $\mathrm{OP}, \mathrm{PM}$ mass, $\mathrm{PNC}_{1} \mathrm{NO}_{2}$ and $\mathrm{O}_{3}$ concentrations during the exposure

\begin{tabular}{|c|c|c|c|}
\hline & All sites $(n=170)$ & Outdoor sites $(n=125)$ & Underground $(n=45)$ \\
\hline OPDTT-PM2.5 $\left(\mathrm{nmol} \mathrm{DTT} / \mathrm{min} / \mathrm{m}^{3}\right)$ & $3.7(0.4-25.7)$ & $2.0(0.4-5.8)$ & $19.3(12.7-25.7)$ \\
\hline $\mathrm{OP}^{\mathrm{DTT}-\mathrm{PM} 10}\left(\mathrm{nmol} \mathrm{DTT} / \mathrm{min} / \mathrm{m}^{3}\right)$ & $5.7(0.8-68.4)$ & $2.3(0.8-6.7)$ & $49.9(38.9-68.4)$ \\
\hline OP ESR-PM2.5 $\left(\mathrm{AU} / 1000 / \mathrm{m}^{3}\right)$ & $12.8(0.5-916.4)$ & $2.9(0.5-19.7)$ & 773.2 (569.7-916.4) \\
\hline $\mathrm{OP}^{\mathrm{ESR}-\mathrm{PM} 10}\left(\mathrm{AU} / 1000 / \mathrm{m}^{3}\right)$ & $30.9(0.7-2612.4)$ & $5.7(0.7-41.4)$ & $2.152 .7(1617.6-2612.4)$ \\
\hline $\mathrm{OP}^{\mathrm{AA}-\mathrm{PM} 2.5}\left(\mathrm{nmol} \mathrm{AA} / \mathrm{s} / \mathrm{m}^{3}\right)$ & $95.6(9.2-2122.2)$ & $32.9(9.2-264.5)$ & $1853.2(1482.4-2122.2)$ \\
\hline $\mathrm{OP}^{\mathrm{AA}-\mathrm{PM} 10}\left(\mathrm{nmol} \mathrm{AA} / \mathrm{s} / \mathrm{m}^{3}\right)$ & $177.5(4.5-5221.8)$ & $48.4(4.5-415.4)$ & $4037.4(3138.2-5221.8)$ \\
\hline $\mathrm{PM}_{2.5}\left(\mu \mathrm{g} / \mathrm{m}^{3}\right)$ & $37.8(8.3-167.1)$ & $23.4(8.3-95.0)$ & $142.0(123.0-167.1)$ \\
\hline $\mathrm{PM}_{10}\left(\mu \mathrm{g} / \mathrm{m}^{3}\right)$ & $70.6(18.1-449.6)$ & $38.0(18.1-130.2)$ & 395.1 (353.7-449.6) \\
\hline PNC $\left(10^{3} / \mathrm{cm}^{3}\right)$ & $23.0(7.0-74.7)$ & $21.0(7.0-74.7)$ & $29.6(14.6-39.8)$ \\
\hline $\mathrm{NO}_{2}(\mathrm{ppb})$ & $20.1(9.0-33.8)$ & $20.2(9.0-33.8)$ & $19.7(14.1-26.0)$ \\
\hline $\mathrm{O}_{3}(\mathrm{ppb})$ & $8.2(0.3-31.8)$ & $18.3(5.8-31.8)$ & $0.9(0.3-0.6)$ \\
\hline
\end{tabular}

$\mathrm{OP}$, oxidative potential; $\mathrm{PM}$, particulate matter; PNC, particle number concentrations; $\mathrm{AU}$, arbitrary units.

models (see online supplementary table S8). In the all sites data set, all measures of OP of $\mathrm{PM}_{2.5}$ were significantly associated with increases in vWF the next morning, and $\mathrm{OP}^{\mathrm{DTT}}$ was significantly associated with increases in TPA/PAI-1 complex.

\section{TWO-POLLUTANT MODELS}

Results from two-pollutant models are presented in detail for $\mathrm{FE}_{\mathrm{NO}}$ and NAL IL-6, as these health parameters were significantly associated with OP in both the all sites and the outdoor only or underground adjusted models. In our previous analyses, $2 \mathrm{~h}$ after exposure, $\mathrm{FE}_{\mathrm{NO}}$ was consistently associated with PNC and NAL IL-6 with $\mathrm{NO}_{2}$, after adjustment for a range of co-pollutants including the OPRLF ${ }^{\mathrm{RT}}$ us in those analyses. ${ }^{13-14}$

\section{Associations including all sites}

Results from two pollutant models for health parameters that showed significant association with $\mathrm{OP}$ are given in the online supplementary tables S9-S15. The significant associations of OP with $\mathrm{FE}_{\mathrm{NO}}$ and NAL-IL6 in single-pollutant models all disappeared after adjusting for PNC ( $\left.\mathrm{FE}_{\mathrm{NO}}\right)$ or $\mathrm{NO}_{2}$ (NAL IL-6), whereas effects of PNC or $\mathrm{NO}_{2}$ were not affected by adjustment for OP (see online supplementary figure S1). Effects of PNC on $\mathrm{FE}_{\mathrm{NO}}$ and of $\mathrm{NO}_{2}$ on NAL IL-6 also remained after adjustment for all other pollutants and cancelled out the effect of all other pollutants (see online supplementary tables S9-S12).

Associations with lactoferrin remained significant after adjustment for co-pollutants, especially for $\mathrm{OP}^{\mathrm{AA}}$ and $\mathrm{OP}^{\mathrm{ESR}}$ (see online supplementary table S13).

\section{Associations after excluding or adjusting for the underground \\ $\mathrm{FE}_{\mathrm{NO}}$ and NAL IL-6}

Results from two-pollutant models for combinations of OP and $\mathrm{PM}$ mass, $\mathrm{PNC}, \mathrm{NO}_{2}$ and $\mathrm{O}_{3}$ for the outdoor sites are shown in figure 1 for $\mathrm{FE}_{\mathrm{NO}}$ and figure 2 for NAL IL-6. Results from twopollutant models with PM composition and results for the underground adjusted models are included in the online supplementary tables S9-S12.

For $\mathrm{FE}_{\mathrm{NO}}$, the significant associations for $\mathrm{OP}^{\mathrm{DTT}}, \mathrm{OP}^{\mathrm{ESR}}$ and $\mathrm{OP}^{\mathrm{AA}}$ of $\mathrm{PM}_{2.5}$ all remained after adjustment for $\mathrm{PM}_{2.5}$ mass, $\mathrm{PNC}, \mathrm{NO}_{2}, \mathrm{O}_{3}$ (figure 1) as well as after adjustment for $\mathrm{PM}_{2.5}$ composition (see online supplementary table S9). Effects of $\mathrm{OP}^{\mathrm{DTT}}$ remained significant after adjustment for $\mathrm{OP}^{\mathrm{ESR}}$ or OP $\mathrm{OP}^{\mathrm{AA}}$, and vice versa. $\mathrm{OP}^{\mathrm{ESR}}$ and $\mathrm{OP}^{\mathrm{AA}}$ were too highly correlated to disentangle their independent effects. Results for OP of $\mathrm{PM}_{10}$ were similar to the results for $\mathrm{PM}_{2,5}$ albeit less consistent for $\mathrm{OP}^{\mathrm{ESR}}$ and $\mathrm{OP}^{\mathrm{AA}}$.

For NAL IL-6, no consistent associations were found for any of the OP-PM 2.5 measures. $\mathrm{PM}_{2.5}$ mass was consistently associated with NAL IL-6 in both the outdoor data set and the underground adjusted model. For $\mathrm{PM}_{10}$, both $\mathrm{OP}^{\mathrm{DTT}}$ and $\mathrm{PM}_{10}$ mass were consistently associated with increases in NAL IL-6, whereas the effects of $\mathrm{OP}^{\mathrm{ESR}}$ and $\mathrm{OP}^{\mathrm{AA}}$ lost significance after adjustment for (among others) $\mathrm{PM}_{10}$ mass and $\mathrm{NO}_{2}$. OP ${ }^{\mathrm{DTT}}$ and $\mathrm{PM}_{10}$ mass were too highly correlated to disentangle their independent effects.

\section{Lung function}

The significant associations in the outdoor data set between OP and lung function $\left(\mathrm{FEV}_{1}\right.$ and $\left.\mathrm{FVC}\right)$ all lost significance when adjusted for several co-pollutants, including $\mathrm{PNC}, \mathrm{NO}_{2}$ and $\mathrm{O}_{3}$ (see online supplementary tables S16and S17).

\section{Associations with previously reported OP metrics}

Associations between the previously reported OP metrics using the current data analysis strategy involving log-transformation did not differ materially from the previously published results with non-transformed OP values (see online supplementary table S18).

Although significant associations were observed between $\mathrm{FE}_{\mathrm{NO}}$ and all three OP ${ }^{\mathrm{RTLF}}$ metrics in the outdoor only and underground adjusted models, these associations all decreased and lost significance when adjusted for (among others) PNC. In addition, associations with $\mathrm{OP}^{\mathrm{RTLF}}$ also lost significance when adjusted for the OP metrics used in the current analyses (ie, $\mathrm{OP}^{\mathrm{DTT}}, \mathrm{OP}^{\mathrm{ESR}}$ and $\mathrm{OP}^{\mathrm{AA}}$ ), whereas effects of these OP metrics remained when adjusted for OP ${ }^{\mathrm{RTLF}}$ (see online supplementary figure S2 and S3).

\section{DISCUSSION}

In single-pollutant models, we found significant associations between three different measures of the OP of PM $\left(\mathrm{OP}^{\mathrm{DTT}}\right.$, $\mathrm{OP}^{\mathrm{ESR}}$ and $\mathrm{OP}^{\mathrm{AA}}$ ) and markers of airway and nasal inflammation ( FE $_{\mathrm{NO}}$ and NAL IL-6) $2 \mathrm{~h}$ after exposure. Effect estimates increased considerably after excluding measurements at the underground train station. Adjusting for, rather than excluding, the underground data resulted in effect estimates similar to effects observed in the outdoor data set. Results from twopollutant models differed substantially depending on how the underground data were considered: For all sites, not OP but 
Table 2 Adjusted associationst between different measures of the $\mathrm{OP}$ of $\mathrm{PM}_{10}$ and $\mathrm{PM}_{2.5}$, and percentage changes in $\mathrm{FE}_{\mathrm{NO}}$, lung function and markers in NAL $2 \mathrm{~h}$ after exposure

\begin{tabular}{|c|c|c|c|c|c|c|}
\hline & \multicolumn{2}{|l|}{ All sites } & \multicolumn{2}{|l|}{ Outdoor only } & \multicolumn{2}{|c|}{ All sites, adjusted underground } \\
\hline & Estimate (\%) & $(95 \% \mathrm{Cl})$ & Estimate (\%) & $(95 \% \mathrm{Cl})$ & Estimate (\%) & $(95 \% \mathrm{Cl})$ \\
\hline \multicolumn{7}{|l|}{$\mathrm{FE}_{\mathrm{NO}} \ddagger$} \\
\hline$O \mathrm{P}^{\mathrm{AA}} \mathrm{PM}_{10}$ & $3.8^{*}$ & (0.8 to 6.8$)$ & $10.0^{* *}$ & (3.5 to 16.4 ) & $9.0^{* *}$ & (2.9 to 15.0$)$ \\
\hline $\mathrm{OP}^{\mathrm{AA}} \mathrm{PPM}_{2.5}$ & $3.6^{* *}$ & (1.1 to 6.2 ) & $13.6^{* *}$ & (7.4 to 19.8$)$ & $13.1^{* *}$ & (7.1 to 19.2 ) \\
\hline $\mathrm{OP} \mathrm{PSR}_{-} \mathrm{PM}_{10}$ & $2.4^{*}$ & (0.5 to 4.4 ) & $9.2^{* *}$ & (3.9 to 14.5 ) & $9.2^{* *}$ & (4.1 to 14.2 ) \\
\hline OPESR $\mathrm{PM}_{2.5}$ & $2.5^{*}$ & (0.6 to 4.4 ) & $10.4^{* *}$ & (5.2 to 15.7 ) & $10.2^{* *}$ & (5.2 to 15.3 ) \\
\hline $\mathrm{OP} \mathrm{PTT}_{-} \mathrm{PM}_{10}$ & $2.2^{*}$ & (0.2 to 4.2 ) & $14.8^{* *}$ & (6.5 to 23.0 ) & $13.9^{* *}$ & (6.8 to 21.0 ) \\
\hline $\mathrm{OP} \mathrm{P}^{\mathrm{DT}} \mathrm{PM}_{2.5}$ & $3.6^{* *}$ & (1.1 to 6.2 ) & $10.8^{* *}$ & (4.7 to 17.0$)$ & $10.9^{* *}$ & (5.4 to 16.5 ) \\
\hline \multicolumn{7}{|l|}{ FVC $\ddagger$} \\
\hline $\mathrm{OP}^{\mathrm{AA}} \mathrm{PM}_{10}$ & -0.22 & $(-0.79$ to 0.34$)$ & $-1.17^{*}$ & $(-2.35$ to 0.00$)$ & -0.94 & $(-2.08$ to 0.20$)$ \\
\hline $\mathrm{OP}^{\mathrm{AA}} \mathrm{PP}_{2.5}$ & -0.12 & $(-0.60$ to 0.35$)$ & -0.98 & $(-2.17$ to 0.21$)$ & -0.85 & $(-2.02$ to 0.32$)$ \\
\hline $\mathrm{OP} \mathrm{PSR}_{-}^{\mathrm{ESM}} \mathrm{PM}_{10}$ & -0.13 & $(-0.50$ to 0.23$)$ & $-1.05^{*}$ & $(-2.02$ to -0.08$)$ & $-0.96^{*}$ & $(-1.91$ to 0.00$)$ \\
\hline $\mathrm{OP}^{\mathrm{ESR}} \mathrm{PM}_{2.5}$ & -0.07 & $(-0.43$ to 0.29$)$ & -0.67 & $(-1.67$ to 0.33$)$ & -0.61 & $(-1.58$ to 0.36$)$ \\
\hline $\mathrm{OP} \mathrm{PTT}_{-} \mathrm{PM}_{10}$ & -0.05 & $(-0.42$ to 0.32$)$ & $-1.50 \#$ & (-3.03 to 0.02$)$ & -0.76 & $(-2.12$ to 0.60$)$ \\
\hline $\mathrm{OP}^{\mathrm{DTT}} \mathrm{PM}_{2.5}$ & 0.03 & $(-0.46$ to 0.51$)$ & -0.09 & $(-1.26$ to 1.07$)$ & 0.05 & $(-1.04$ to 1.15$)$ \\
\hline \multicolumn{7}{|l|}{$\mathrm{FEV}_{1} \ddagger$} \\
\hline $\mathrm{OP}^{\mathrm{AA}}-\mathrm{PM}_{10}$ & -0.33 & $(-0.86$ to 0.20$)$ & $-1.29^{*}$ & $(-2.37$ to -0.21$)$ & -1.00 & $(-2.08$ to 0.07$)$ \\
\hline $\mathrm{OP}^{\mathrm{AA}} \mathrm{PPM}_{2.5}$ & -0.25 & $(-0.70$ to 0.21$)$ & $-1.17^{*}$ & $(-2.31$ to -0.04$)$ & -1.03 & $(-2.16$ to 0.10$)$ \\
\hline $\mathrm{OP}^{\mathrm{ESR}} \mathrm{PM}_{10}$ & -0.20 & $(-0.54$ to 0.14$)$ & $-1.09^{*}$ & $(-1.99$ to -0.18$)$ & $-1.01^{*}$ & $(-1.91$ to -0.11$)$ \\
\hline $\mathrm{OP} \mathrm{PSR}_{-}^{\mathrm{ESR}} \mathrm{PM}_{2.5}$ & -0.19 & $(-0.53$ to 0.16$)$ & $-0.95^{*}$ & $(-1.90$ to 0.00$)$ & $-0.96^{*}$ & $(-1.89$ to -0.02$)$ \\
\hline $\mathrm{OP} \mathrm{PTT}_{-} \mathrm{PM}_{10}$ & -0.11 & $(-0.46$ to 0.24$)$ & -1.08 & $(-2.52$ to 0.36$)$ & -0.63 & $(-1.91$ to 0.66$)$ \\
\hline $\mathrm{OP} \mathrm{PTT}_{-} \mathrm{PM}_{2.5}$ & -0.07 & $(-0.54$ to 0.40$)$ & -0.15 & $(-1.27$ to 0.98$)$ & 0.01 & $(-1.05$ to 1.07$)$ \\
\hline \multicolumn{7}{|l|}{ NAL IL-6§ } \\
\hline $\mathrm{OP}^{\mathrm{AA}} \mathrm{PM}_{10}$ & $14.7^{\star}$ & (2.3 to 28.7 ) & $30.3^{*}$ & (3.6 to 64.0 ) & $36.9^{* *}$ & (8.3 to 72.9 ) \\
\hline $\mathrm{OP}^{\mathrm{AA}} \mathrm{PP}_{2.5}$ & $10.7^{*}$ & (1.2 to 21.1 ) & 17.8 & (-2.9 to 42.8$)$ & $23.3^{*}$ & (0.9 to 50.7$)$ \\
\hline OPESR ${ }^{E-} \mathrm{PM}_{10}$ & $7.9^{*}$ & (0.3 to 16.0$)$ & $23.5^{*}$ & (2.1 to 48.9 ) & $27.8^{*}$ & (4.9 to 55.0 ) \\
\hline OPESR ${ }^{\mathrm{ESM}} \mathrm{P}_{2.5}$ & 6.8 & $(-0.2$ to 14.2$)$ & 10.9 & $(-5.8$ to 30.5$)$ & 13.0 & ( -4.7 to 34.1$)$ \\
\hline $\mathrm{OP} \mathrm{P}^{\mathrm{DT}} \mathrm{PM}_{10}$ & $8.8^{*}$ & (1.5 to 16.5 ) & $39.2^{* *}$ & (14.6 to 69.0$)$ & $41.5^{* *}$ & (17.2 to 70.9 ) \\
\hline $\mathrm{OP} \mathrm{P}^{\mathrm{DT}} \mathrm{PM}_{2.5}$ & $12.4^{\star *}$ & (3.3 to 22.2 ) & $20.0^{*}$ & (1.1 to 42.4 ) & 29.0 ** & (9.1 to 52.7 ) \\
\hline \multicolumn{7}{|l|}{ NAL protein§ } \\
\hline $\mathrm{OP}^{\mathrm{AA}} \mathrm{PM}_{10}$ & 2.9 & (-5.6 to 11.4$)$ & $16.5^{*}$ & (0.7 to 32.4 ) & 11.8 & (-5.7 to 29.2 ) \\
\hline $\mathrm{OP}^{\mathrm{AA}} \mathrm{PPM}_{2.5}$ & 2.2 & ( -4.3 to 8.7$)$ & 11.8 & $(-1.3$ to 24.9$)$ & 10.4 & ( -4.3 to 25.0$)$ \\
\hline $\mathrm{OP}^{\mathrm{ESR}} \mathrm{PM}_{10}$ & 1.2 & $(-4.1$ to 6.6$)$ & 8.9 & ( -4.3 to 22.1$)$ & 9.0 & $(-5.6$ to 23.5$)$ \\
\hline $\mathrm{OP}^{\mathrm{ESR}} \mathrm{PM}_{2.5}$ & 1.0 & $(-3.8$ to 5.9$)$ & 6.4 & (-4.8 to 17.5$)$ & 5.9 & (-6.5 to 18.2$)$ \\
\hline $\mathrm{OP} \mathrm{PTT}_{\mathrm{DT}} \mathrm{PM}_{10}$ & 1.2 & ( -3.8 to 6.2$)$ & 11.4 & (-2.7 to 25.4$)$ & 9.6 & (-4.8 to 24.0$)$ \\
\hline $\mathrm{OP} \mathrm{P}^{\mathrm{DT}} \mathrm{PM}_{2.5}$ & 1.5 & ( -4.7 to 7.6$)$ & 6.1 & $(-5.7$ to 17.9$)$ & 5.4 & (-7.1 to 17.8$)$ \\
\hline \multicolumn{7}{|l|}{ NAL lactoferrin§ } \\
\hline $\mathrm{OP}^{\mathrm{AA}}{ }_{-} \mathrm{PM}_{10}$ & $20.9^{*}$ & (3.6 to 41.0 ) & 24.7 & (-6.5 to 66.5$)$ & 25.3 & (-8.6 to 71.7 ) \\
\hline $\mathrm{OP}^{\mathrm{AA}} \mathrm{PPM}_{2.5}$ & $14.0^{*}$ & (1.2 to 28.5 ) & 13.1 & $(-11.6$ to 44.6$)$ & 13.8 & $(-13.1$ to 48.9$)$ \\
\hline $\mathrm{OP}^{\mathrm{ESR}}{ }_{-} \mathrm{PM}_{10}$ & $11.2^{*}$ & (0.9 to 22.6 ) & 14.9 & (-9.4 to 45.8$)$ & 12.0 & $(-14.0$ to 45.8$)$ \\
\hline $\mathrm{OP} \mathrm{PSR}_{-} \mathrm{PM}_{2.5}$ & $10.5^{*}$ & (1.1 to 20.7 ) & 15.2 & (-6.2 to 41.4$)$ & 12.4 & $(-10.3$ to 40.8$)$ \\
\hline $\mathrm{OP} \mathrm{PTT}_{-} \mathrm{PM}_{10}$ & $9.6^{*}$ & (0.0 to 20.0$)$ & 8.0 & (-16.4 to 39.6$)$ & 4.8 & (-19.4 to 36.3$)$ \\
\hline $\mathrm{OP}^{\mathrm{DTT}} \mathrm{PM}_{2.5}$ & 10.1 & $(-1.6$ to 23.3$)$ & -0.2 & (-19.8 to 24.1$)$ & 0.6 & (-19.9 to 26.4$)$ \\
\hline
\end{tabular}

$\mathrm{PNC}$ and $\mathrm{NO}_{2}$ remained significantly associated with $\mathrm{FE}_{\mathrm{NO}}$ and NAL IL-6, respectively, whereas after excluding the underground we found consistent associations with OP. Other health end points, including lung function and vascular inflammatory and coagulation parameters in blood were not consistently associated with OP.

In previous publications from the RAPTES project, no consistent associations with OP were found in either the all sites or the outdoor data set. ${ }^{13-15}$ In those analyses, OP was calculated as the sum of OP from $\mathrm{PM}_{0.18}, \mathrm{PM}_{0.18-2.5}$ and $\mathrm{PM}_{2.5-10}$ collected with a MOI and measured as the capacity of PM to deplete the antioxidants AA and glutathione (GSH) in a synthetic human RTLF. Our results suggest that the health relevance of OP ${ }^{\text {RTLF }}$, as measured with an MOI sampler in the previous study, is less than the health relevance of the three OP metrics, as measured on $\mathrm{PM}_{10}$ and $\mathrm{PM}_{2.5}$ filters, in the current study. We cannot 

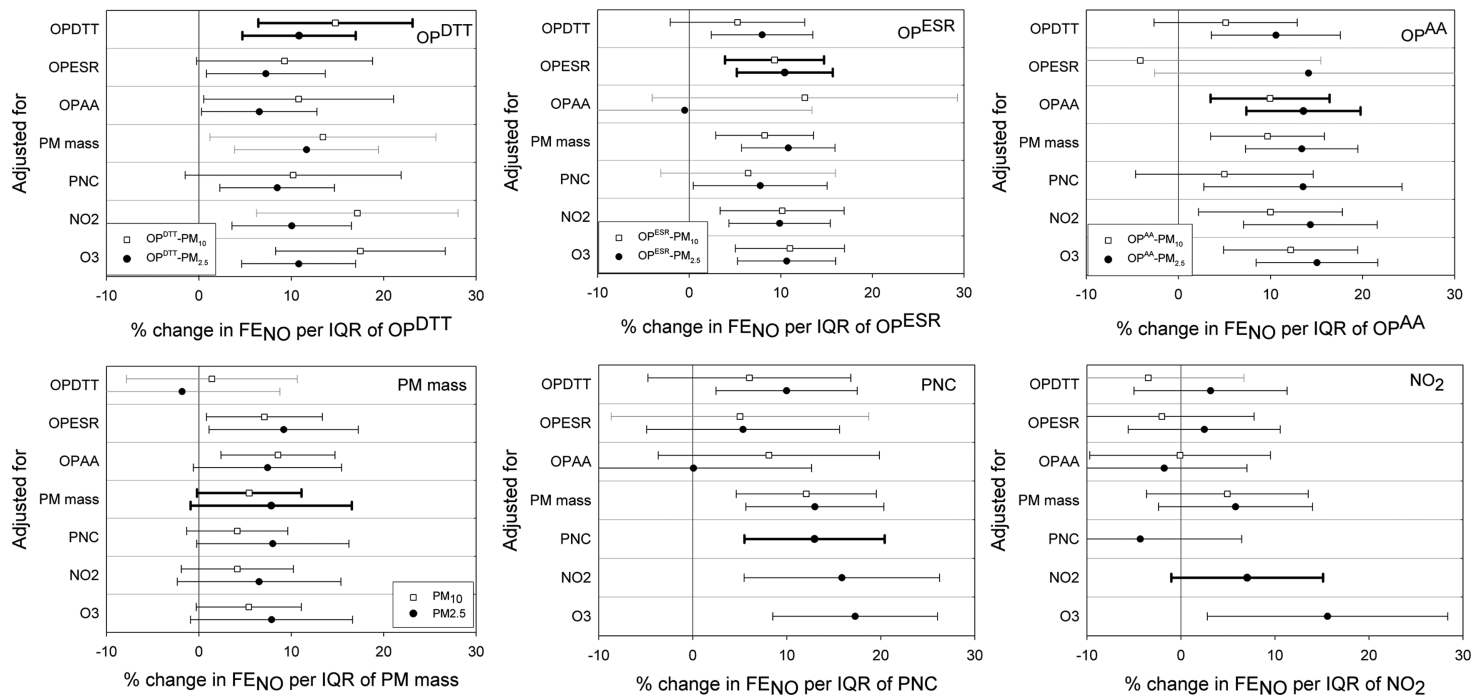

Figure 1 Associations between oxidative potential (OP) of particulate matter (PM), PM mass, particle number concentration (PNC), $\mathrm{NO}_{2}$ and $\mathrm{FE}_{\mathrm{NO}}$ in single-pollutant and two-pollutant models after excluding the underground. Single-pollutant effect estimates in bold; grey indicates high $(>0.7)$ correlation between the two pollutants (see online supplementary table S6-57).

disentangle between the impact of the different sampling methods (HI vs MOI) and impact of the different OP assays (current assays vs $\mathrm{OP}^{\mathrm{RTLF}}$ ), but speculate that sampling played a major role, based on the rather poor agreement between MOI mass and $\mathrm{HI}$ mass. ${ }^{16}$ We documented that the $\log$ transformation of exposure did not explain the difference between the current OP findings and our previous publications (see online supplementary table S18).

When comparing the different assays used in the current study, after excluding the underground, all three measures of the OP of $\mathrm{PM}_{2.5}$ were consistently associated with $\mathrm{FE}_{\mathrm{NO}}$ : effects of $\mathrm{OP}^{\mathrm{DTT}}$ remained after adjustment for $\mathrm{OP}^{\mathrm{ESR}}$ or $\mathrm{OP}^{\mathrm{AA}}$ and vice versa, suggesting that (drivers of) $\mathrm{OP}^{\mathrm{DTT}}$ and (drivers of) $\mathrm{OP}^{\mathrm{ESR}}$ or $\mathrm{OP}^{\mathrm{AA}}$ can have independent effects on $\mathrm{FE}_{\mathrm{NO}}$. $\mathrm{OP}{ }^{\mathrm{ESR}}$ and $\mathrm{OP}^{\mathrm{AA}}$ were too highly correlated to disentangle their independent effects. For NAL IL-6, consistent associations with OP were only observed for $\mathrm{OP}^{\mathrm{DTT}}$ of $\mathrm{PM}_{10}$, which could not be disentangled from effects of $\mathrm{PM}_{10}$ mass. Different PM components contribute to $\mathrm{OP}^{\mathrm{DTT}}$ compared with $\mathrm{OP}^{\mathrm{ESR}}$ or $\mathrm{OP}^{\mathrm{AA}}$, and $\mathrm{OP}$ is not easily predicted by single chemical. ${ }^{16}$ In our study, OP ${ }^{\mathrm{DTT}}$ showed the highest correlation with PM mass, OC (for $\mathrm{OP}^{\mathrm{DTT}-\mathrm{PM} 2.5}$ ) and $\mathrm{NO}_{2}$ (for $\mathrm{OP}^{\mathrm{DTT}-\mathrm{PM} 10}$ ), whereas $\mathrm{OP}^{\mathrm{ESR}}$ and $\mathrm{OP}^{\mathrm{AA}}$ showed the highest correlation with the traffic-related $\mathrm{PM}$ component (eg, $\mathrm{Fe}, \mathrm{Cu}, \mathrm{EC}$ ), especially for $\mathrm{PM}_{10}$. As none of the measured individual PM components was consistently positively associated with $\mathrm{FE}_{\mathrm{NO}}$ or NAL IL-6, this suggests that different assays could provide complementary information regarding the oxidative properties of PM and their associated health effects. The observed changes most likely do not reflect adverse clinical effects, but they do show that, at ambient levels, different air pollutants can trigger biological responses in healthy, young adults.
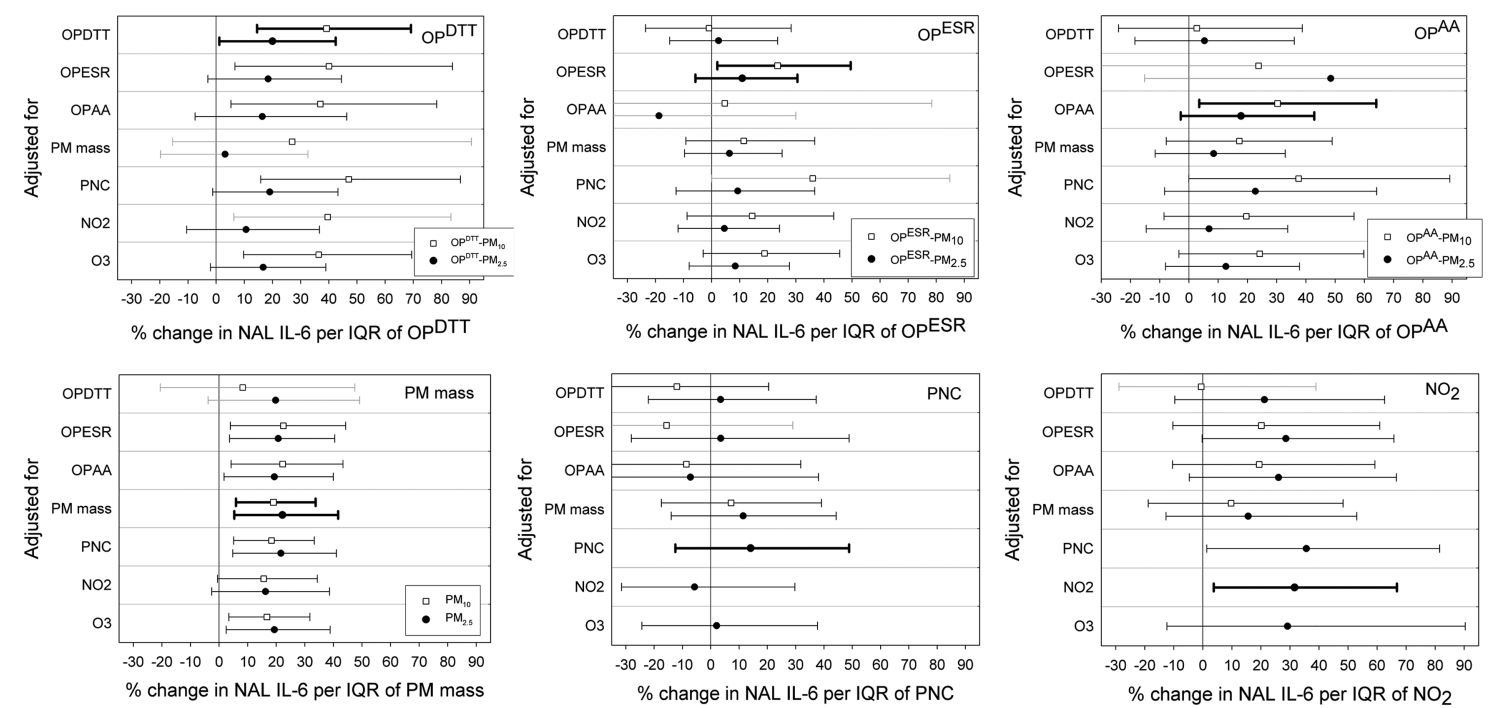

Figure 2 Associations between oxidative potential (OP) of particulate matter (PM), PM mass, particle number concentration (PNC), $\mathrm{NO}_{2}$ and nasal lavage (NAL) interleukin (IL)-6 in single-pollutant and two-pollutant models after excluding the underground. Single-pollutant effect estimates in bold; grey indicates high (>0.7) correlation between the two pollutants (see online supplementary table S6-S7). 
When all sites were considered, OP was not associated with increases in $\mathrm{FE}_{\mathrm{NO}}$ or NAL IL-6 after adjustment for co-pollutants. The differences in results, depending on how the underground is considered, are difficult to explain. In previous publications, we also observed differences in results for the all sites compared to the outdoor only models, especially for components that were highly elevated at the underground site. When the underground site was included in the analysis, $\mathrm{FE}_{\mathrm{NO}}$ and NAL IL-6 were consistently associated with PNC and $\mathrm{NO}_{2}$, respectively; two components that were not (substantially) elevated in the underground compared with the outdoor locations. ${ }^{15}$ In an in vitro study, including samples from the five locations of the current study and three additional sites, a significant association between $\mathrm{OP}^{\mathrm{DTT}}$ and pro-inflammatory activity was only observed after excluding the underground sample. However, the sample from the underground site was by far the most cytotoxic, which could have hampered the cellular responsiveness of that sample. ${ }^{19}$ In another in vitro study, particles from a subway station in Stockholm were less potent to induce inflammatory cytokines compared with particles from an urban street. ${ }^{20}$ Few studies have investigated the health effects of exposures in the underground settings. ${ }^{21-24}$ Although these studies also measured high concentrations of air pollutants, they could not provide strong evidence of associations between exposure to air pollution and cardiorespiratory health effects. Overall, results from these in vitro and epidemiological studies suggest that the air pollution mixture and associated health effects in the underground are different from the outdoor environment. Alternatively, the lack of associations with OP when including the underground data suggests that the value of OP to predict health effects may be limited and cannot be easily extended to other exposure settings.

Few studies have investigated associations between OP of PM and acute health effects. The associations found for $\mathrm{FE}_{\mathrm{NO}}$ in the outdoor data set are in line with two panel studies in California. ${ }^{11}{ }^{12}$ Delfino et $a l^{11}$ studied the relationship between air pollution and weekly measurements of $\mathrm{FE}_{\mathrm{NO}}$ in a panel of 60 elderly participants living in four retirement communities in the LA basin. A cellular macrophage ROS assay was used to characterise OP of 5-day aggregated $\mathrm{PM}_{0.25}$ samples and an IQR change in ROS was associated with a $4 \%$ increase in $\mathrm{FE}_{\mathrm{NO}}$. In a study among 45 schoolchildren with persistent asthma, both the macrophage ROS assay and the DTT assay were used to characterise $\mathrm{OP}$ of $\mathrm{PM}_{2.5 .}{ }^{12} \mathrm{FE}_{\mathrm{NO}}$ was significantly positively associated with lag 1-day and 2-day averages of both macrophage ROS (3-5\% increase per IQR) and OP ${ }^{\mathrm{DTT}}(9-10 \%$ increase per IQR). ${ }^{12}$

Apart from the observed associations with $\mathrm{FE}_{\mathrm{NO}}$ and NAL IL-6, none of the other health end points, including lung function, total protein in NAL and vascular inflammatory and coagulation parameters in blood were consistently associated with OP. In contrast, in our previous studies we did report associations for these end points with pollutants such as $\mathrm{NO}_{2}$, OC and sulfate/nitrate. ${ }^{13-15}$ Although some significant associations with OP were observed in single-pollutant models in either the all sites or outdoor only models for lung function, vWF and TPA/PAI1 complex, these associations lost significance when adjusted for co-pollutants. The only exception was lactoferrin in the all sites data set, which remained significantly associated with especially $\mathrm{OP}^{\mathrm{ESR}}$ and $\mathrm{OP}^{\mathrm{AA}}$. Given the lack of association between lactoferrin and OP in the outdoor data set, these associations were likely driven by the high exposures at the underground, as was also observed in our previous analyses. ${ }^{14}$
The lack of association for blood IL- 6 contrasts with findings from the study among the elderly by Delfino et al, ${ }^{11}$ in which an IQR change in macrophage ROS was associated with a significant 9\% increase in blood IL-6. This inconsistency with our findings could be related to differences in design, study population and OP metric that was used (ie, $5 \mathrm{~h}$ average OP of $\mathrm{PM}_{2.5}$ and $\mathrm{PM}_{10}$ from a-cellular assays vs macrophage ROS of 5-day aggregated $\mathrm{PM}_{0.25}$ samples). In general, absence of associations with OP in our study may be related to the fact that the assays employed only examined the intrinsic potential of the particles to drive oxidation reactions in an a-cellular model, reflecting their content of redox active compounds rather than on interaction with a biological system. As PM can elicit oxidative stress through alternative pathways on interaction with the cellular/ tissue matrix, an a-cellular assay does not necessarily reflect the total oxidative activity in vivo. ${ }^{9}$

Strengths and limitations of our design were discussed in detail previously. ${ }^{13-15}$ Among others, since we performed air pollution characterisation on-site during exposure of volunteers, exposure measurement error was small compared with observational studies relying on data from central monitoring sites. In our design, we also reduced correlations between PM characteristics by performing repeated measurements at multiple locations with different source characteristics. Despite that, some correlations remained too high to interpret two-pollutant models and disentangle independent effects of OP from other PM characteristics (eg, $\mathrm{OP}^{\mathrm{DTT}}$ and $\mathrm{PM}_{10}$ mass in relation to NAL IL-6). As we evaluated a large number of models, we potentially faced a problem of chance findings in our results. That is why, in our interpretation of the results, we focused on the consistency of (significant) associations rather than individual significant associations.

\section{CONCLUSION}

We found significant associations between three a-cellular measures of OP of PM and markers of airway and nasal inflammation in healthy young adults. These OP associations remained significant after adjustment for co-pollutants when the four outdoor sites were included, but lost significance when measurements at the underground site were included. Lung function and vascular inflammatory and coagulation parameters in blood were not consistently associated with OP. Our study, therefore, provides limited support for a role of OP in predicting acute health effects of PM in healthy adults. The difference in associations with different health end points in our study adds to the complexity of investigating which particle metric is more relevant in predicting health effects. Additional studies on the relation between OP and a range of health effects are needed to draw more firm conclusions on the added value of OP compared with more established metrics. Studies in susceptible populations and studies on effects of long-term exposure are needed to further evaluate the added value of OP in future air monitoring and assessments.

\footnotetext{
Author affiliations

${ }^{1}$ Centre for Sustainability, Environment and Health, National Institute for Public Health and the Environment (RIVM), Bilthoven, The Netherlands

${ }^{2}$ Institute for Risk Assessment Sciences, Utrecht University, Utrecht, The Netherlands ${ }^{3}$ Department of Environmental Health, Public Health Service (GGD) Amsterdam, Amsterdam, The Netherlands

${ }^{4}$ Air Quality \& Sustainable Nanotechnology, Institute of Energy and Environmental Technology (IUTA), Duisburg, Germany

${ }^{5}$ CENIDE, University of Duisburg-Essen, Duisburg, Germany

${ }^{6}$ MRC-PHE Centre for Environment and Health, School of Biomedical Sciences,

King's College London, London, UK

${ }^{7}$ Division of Environmental Health \& Risk Management, School of Geography, Earth \& Environmental Sciences, University of Birmingham, Birmingham, UK
} 
${ }^{8}$ Department of Environmental Sciences, Center of Excellence in Environmental Studies, King Abdulaziz University, Jeddah, Saudi Arabia

${ }^{9}$ Julius Center for Health Sciences and Primary Care, University Medical Center Utrecht, Utrecht, The Netherlands

Contributors NAHJ, MStr, FJK, RMH, BB, FRC, MSte and GH were involved in conception and design of the RAPTES study. NAHJ, BB and GH contributed to the data analyses strategy of the current study. NAHJ performed the statistical analyses and drafted the manuscript. MStr and MSte organised and carried out the fieldwork and assisted in the statistical analyses. AY, BH and TAJK contributed to the analyses and interpretation of the oxidative potential measurements used in the current study. FJK supervised the earlier oxidative potential analyses. RMH supervised the chemical analyses in the study. All authors reviewed and approved the manuscript.

Funding The study was funded by the RIVM Strategic Research programme (S630002 and S630021) and the Dutch Ministry for Infrastructure and the Environment (M630196).

Competing interests None.

Patient consent Obtained.

Ethics approval University Medical Centre Utrecht.

Provenance and peer review Not commissioned; externally peer reviewed.

\section{REFERENCES}

1 Brunekreef B, Holgate ST. Air pollution and health. Lancet 2002;360:1233-42.

2 Pope CA III, Dockery DW. Health effects of fine particulate air pollution: lines that connect. J Air Waste Manage Assoc 2006;56:709-42.

3 Brunekreef B. The color of smoke. Epidemiology 2010;21:903-4.

4 World Health Organization. Health relevance of particulate matter from various sources. Report on a WHO workshop. Copenhagen: WHO regional Office for Europe, 2007.

5 World Health Organization. Review of evidence of health aspects of air pollutionREVIAAP Project, technical report. Copenhagen: WHO regional Office for Europe, 2013.

6 Nel A. Air pollution related illness: effects of particles. Science 2005;308:804-6.

7 Xia $T$, Kovochich $M$, Nel $A$. The role of reactive oxygen species and oxidative stress in mediating particulate matter injury. Clin Occup Environ Med 2006;5:817-36.

8 Borm PJA, Kelly F, Kunzli N, et al. Oxidant generation by particulate matter: from biologically effective dose to a promising novel metric. Occup Environ Med 2007;64:73-4

9 Ayres JG, Borm P, Cassee FR, et al. Evaluating the toxicity of airborne particulate matter and nanoparticles by measuring oxidative stress potential-a workshop report and consensus statement. Inhal Toxicol 2008;20:75-99.

10 Boogaard $\mathrm{H}$, Janssen $\mathrm{NAH}$, Fischer $\mathrm{PH}$, et al. Contrasts in oxidative potential and other particulate matter characteristics collected near major streets and background locations. Environ Health Perspect 2012;120:185-91.
11 Delfino DJ, Staimer N, Tjoa T, et al. Association of primary and secondary organic aerosols with airway and systemic inflammation in an elderly panel cohort. Epidemiology 2010;21:892-902.

12 Delfino RJ, Staimer N, Tjoa T, et al. Airway inflammation and oxidative potential of air pollutant particles in a pediatric asthma panel. J Exp Sci Environ Epidemiol 2013:23:466-73.

13 Strak M, Janssen NAH, Godri KJ, et al. Respiratory health effects of airborne particulate matter: the role of particle size, composition and oxidative potentialthe RAPTES project. Environ Health Perspect 2012;120:1183-9.

14 Steenhof M, Mudway IS, Gosens I, et al. Acute nasal pro-inflammatory response to air pollution depends on characteristics other than particle mass concentration or oxidative potential: the RAPTES project. Occup Environ Med 2013;70:341-8.

15 Strak M, Hoek G, Godri KJ, et al. Composition of PM affects acute vascular inflammatory and coagulative markers - the RAPTES project. PLOS ONE 2013;8: e58944.

16 Janssen $\mathrm{NAH}$, Yang $\mathrm{A}$, Strak $\mathrm{M}$, et al. Oxidative potential of particulate matter collected at sites with different source characteristics. Sci Total Environ 2014;472:572-81.

17 Strak M, Steenhof M, Godri KJ, et al. Variation in characteristics of ambient particulate matter at eight locations in the Netherlands - the RAPTES project. Atmospheric Environ 2011;45:4442-53.

18 Yang $A$, Jedynska A, Hellack $B$, et al. Measurement of the oxidative potential of PM2.5 and its constituents: The effect of extraction solvent and filter type. Atmospheric Environ 2014;83:35-42.

19 Steenhof M, Gosens I, Strak M, et al. In vitro toxicity of particulate matter (PM) collected at different sites in the Netherlands is associated with PM composition, size fraction and oxidative potential — the RAPTES project. Particle Fibre Toxicol 2011;8:26.

20 Karlsson HL, Ljungman AG, Lindbom J, et al. Comparison of genotoxic and inflammatory effects of particles generated by wood combustion, a road simulator and collected from street and subway. Toxicol Letters 2006:165:203-11.

21 Bigert $C$, Alderling $M$, Svartengren $M$, et al. Blood markers of inflammation and coagulation and exposure to airborne particles in employess in the Stockholm underground. Occup Environ Med 2008;65:655-8.

22 Bigert $C$, Alderling $M$, Svartengren $M$, et al. No short-term respiratory effects among particle-exposed employess in the Stockholm subway. Scan J Work Environ Health 2011;37:129-35.

23 Grass DS, Ross JM, Family F, et al. Airborne particulate metals in the New York City subway: a pilot study to assess the potential for health impacts. Environ Res 2010;110:1-11.

24 Klepczynska Nystrom A, Svartengren M, Grunewald J, et al. Health effects of a subway environment in healthy volunteers. Eur Respir J 2010;36:240-8. 